\title{
Modern application of marketing in the telecommunications industry
}

\author{
Zhumabek Tumbay ${ }^{1 *}$, Aigul Boltayeva ${ }^{1}$, Zhuldyzai Zhorabayeva ${ }^{1}$, Baglan Aliyeva ${ }^{1}$, and \\ Ayim Sartimbetova ${ }^{l}$ \\ ${ }^{1}$ Al-Farabi Kazakh National University , 050040, 71 Al-Farabi Ave, Almaty, Kazakhstan
}

\begin{abstract}
The article discusses the use of marketing tools in the telecommunications industry, analyzes the experience of their creation and implementation, as well as the role of marketing in this industry. It is simply impossible to imagine the current modern generation without telecommunication technologies. These technologies are so "ingrained" in our lives that it is simply unrealistic to imagine our existence without them. But some people do not even notice these important modern technologies, so companies are experiencing difficulties in relation to the position in the market. So let's try in this article to understand what it is and why do we need telecommunications in the modern world? And is it worth promoting these telecommunications technologies through marketing communications? Are telecommunications currently being promoted through marketing tools?
\end{abstract}

\section{Introduction}

This topic is relevant because the modern system of international economic relations is undergoing a process of intensive development. This is due to significant changes in the international division of labor, the strengthening of integration trends, and changes in the political configuration of the world, the transition to a new structure of the balance of forces and interests. The emphasis in the international division of labor is shifting to the technological level. There is a new market segment in the world economy, which is named as TIMES (telecommunications, information, multimedia, entertainment, services) and based on information, post-industrial technologies. The development of telecommunications is one of the sources of ensuring the functioning and recovery of the state's economy. The huge dynamism of modern world economic relations caused a sharp increase in demand for telecommunications services. Along with the increase in demand, there is another very important side: the emergence of strong competitors in the market. So now on the market of telecommunications are being actively used as marketing tools. The purpose of the work is to understand the term telecommunications, to identify the use of marketing communications in this sector in the modern world. The object of the study is the telecommunications industry in General.

\footnotetext{
* Corresponding author: doptaganka@yandex.ru
} 
In accordance with the aim to highlight the tasks that are in progress should be solved: the definition of the entities of the marketing and telecommunications industry through the study of literature; definition of the important criteria of marketing in the industry; studying the actual state of marketing in the telecommunications sector around the world: the development of possible tools for the development of this sector through the use of marketing communications.

\section{Literature review}

The telecommunications industry began in the 1830s with the invention of the Telegraph, the first mechanical communication device. This has reduced the speed of data exchange from a few days to a few hours - just as modern mobile technologies have reduced the time interval for sending large amounts of data from hours to seconds. The industry expanded with each new invention: telephone, radio, television, computer, mobile device. These technological advances have changed the way people live and do business.

Telecommunications once required physical wires that connected homes and businesses. In today's society, technology has become mobile. Currently, wireless digital technology is becoming the main form of communication.

The world economy has undergone a radical transformation in the last two decades due to the technological revolution. Geographical and cultural distances seem to be shortened with the advent of airplanes, faxes, global computers, telephone connections and worldwide satellite broadcasting. These progressive advances have enabled companies to significantly expand both their markets and the source of their suppliers. [1] According to Doyle, [2] the business has moved from offering to unconditional encirclement. Priority management is how to identify and develop products and services that are more attractive to customers than competitors. Therefore, at this stage we can consider the concept of marketing. As it helps to identify and develop goods and services, as well as to engage in their promotion in the market.

Every day and everywhere we are faced with various manifestations of marketing.

"Marketing is a practical activity, a system of management functions, with the help of which organize and manage a set of activities related to the evaluation of the purchasing power of consumers, with its transformation into a real demand for products and services and the approximation of these products and services to customers for profit or any other purpose" [3].

According to the Guild of marketers, "marketing is the process of identifying, predicting and creating customer needs and desires and organizing all the resources of the company to meet them with greater overall profit for the company and the consumer" [4]. Similarly, professors Evans and Berman distinguish marketing as "foreseeing, managing and meeting the demand for goods, services, organizations, territories and ideas through exchange" [5].

What is meant by the term telecommunications? According to Mueller, telecommunications is understood as the whole complex of technical means that are designed to transmit information over any distance. To this complex of technical means it is possible to carry: a sound, a signal, the text, a sign, the written image and many other types. All these means are transmitted by cable, optical, radio and other electromagnetic systems [6].

The system of technical means by which telecommunications is carried out is called a telecommunication network. The telecommunications network is one of the most important features of all technologies: you have the ability to obtain information or data to ensure the operation of any telecommunications participants or to meet the personal needs of users.

Technical means of telecommunications include: equipment and machines used for data processing that transmit or receive telecommunications messages. 
The participants of the telecommunication activities include:

1. Legal and natural persons of the state, as well as foreign legal and natural persons who may provide services in this field;

2. Authorized body-the body regulating activities carried out in the relevant field-in the field of telecommunications;

3. Users of telecommunications services.

Although in our time the telecommunications industry is well developed and quite relevant, but we must not forget that our society is developing every day, every minute different knowledge increases and therefore science does not stand in one place and will never stand. Thus, telecommunications also keep pace with the times and I would like to list promising areas of telecommunications technology:

1. Creation of intelligent antenna devices with improved energy;

2. Creation of telecommunication systems in a very small wave range $(\sim 1 \mathrm{~mm})$ with an operating frequency that will reach up to $100 \mathrm{ghz}$;

3. Create new code modulations by applying a combination of methods of manipulation signals, and new methods of signal coding to increase the bandwidth of the transmission systems and improving their energy;

4. Development of new methods of design and production of telecommunications equipment, which ensures the emergence of more powerful machines that will perform a huge number of tasks.

In addition, do not forget that telecommunications have long been part of the world of computer technology. And, perhaps, in the near future, soon completely immersed in this world. With television, this process is already ongoing. Most countries use digital transmission, which is rapidly displacing their counterparts. In addition, the telecommunications industry earns good money and sales of digital set-top boxes for conventional TVs, has the ability to make some television channels on a paid basis, as in broadcast satellites.

And this is not all prospects for the future in this direction! As you have noticed, the telecommunications industry is closely related to other scientific industries such as physics, energy, electronics, computer science and soon networks will cover even more industries [7].

Nevertheless, the prospects for the development of the telecommunications market should be assessed optimistically, because companies that conduct active marketing policies are less vulnerable to adverse market conditions. Examples of active marketing activities include wide promotions for new offers, a good system of payment for international calls (a fixed monthly tariff plus a reduced tariff per minute of conversation), special tariffs for mobile users depending on traffic, etc.

For example, the complexity and versatility of the market activities of telecommunications firms shows the need to develop a more reasonable scheme of planning market research in this market.

In the field of telecommunications, marketing is different from the classical one, as the sphere itself has an infrastructural character, as well as the fact that the role of the media and the Internet in modern society is growing. The peculiarity of marketing is that the telecommunication type of communication, and usually the subscriber can not assess the quality of services provided, and this is a problem for business marketing. And in this regard, they are forced to look for different methods of approach to the subscriber.

Different approaches are used to attract more customers, increase the subscriber base and increase the profitability of services. Since the services of telecommunications companies are the same, and for the consumer the main role is played only by the price of them. 
An important role in the modern application of marketing in the telecommunications structure is played by:

1. sales policy. The marketing concept is not limited to the creation of a quality product that meets the needs of customers and the right set of standards. It is also necessary to bring the service to consumers in an appropriate way. Therefore, the company's strategy in the field of distribution is aimed at determining the best ways to implement services. The strength of the marketing flow lies primarily in the development of multigenerational diffusion models and their success in predicting demand across industries. These studies also provide valuable information about the dynamics of distribution, timing of market entry. I believe that the main reason why the proposed policy is not consistent with many industry practices is that capacity constraints, inventory costs, policies and lost sales are ignored.

2. price policy. The further competitiveness of the company depends on well-chosen tariffs. The flow of customers to the company will depend on how low the price of the services provided will be. Introduction pricing has always been an integral part of marketing; of the traditional elements of marketing, only pricing generates revenue.

3. product policy. In the product policy it is very important to pay attention to the range of services provided. And so today's Telecom operators work in several areas of the telecommunications market. For example, local operators provide Internet and even cable TV in digital format.

According to Professor S. Ziyadin: the current state of scientific research in the field of digital business transformation strategy reveals options such as organizations in digital form, changes and outlines of internal inspirations of organizations, as well as their external provoking factors.

5 main trends in the telecommunications industry in 2019:

1. $5 \mathrm{~g}$ networks: Telecom Operators are working to build $5 \mathrm{G}$ networks to trigger a huge wave of fast Internet. Although the technology is not yet fully defined, operators are continuing their laboratory and field testing in their race to remain competitive. Full $5 \mathrm{~g}$ mass market coverage is expected by around 2020.

2. Safe and reliable services. The modern telecommunications environment offers a rich set of services that require reliable and secure authentication. The number of smartphones equipped with biometric fingerprint readers is growing. The technology is also used by retailers, financial institutions, government and even schools to verify identity. Other biometric mechanisms, such as facial or retinal recognition, are also trends in telecommunications and are likely to gain strength in the coming years. A growing number of telecommunications companies are using biometric SIM cards to combat mobile phone crimes and terrorist attacks.

3. Artificial intelligence (AI) - adding artificial intelligence (AI) capabilities to smartphones will bring the next shift in technology, according to Huawei, in a ZDNet article. AI allows smartphones to perform very complex functions such as augmented reality (think Pokémon Go), speech recognition, indoor navigation and even learning everyday tasks and human preferences to enable digital assistants such as Siri and Alexa. Customer service chat rooms, such as CenturyLink's "sales consultant", speech and voice services for customers where they can research or purchase content through speech, traffic classification, network optimization and orchestration, and predictive network maintenance, such as AT \& T's self-healing and self-learning hardware. this is powered by artificial intelligence, among some AI applications that are used by leading players and are among the emerging trends in the telecommunications sector. Artificial intelligence is increasingly invading the world. In the 90 s and early 21 st century, artificial intelligence achieved its greatest success. There are more and more jobs being left to robots like exploring another planet, defusing bombs, exploring inside a volcano or just doing boring chores like 
cleaning. Computers can perform many functions: they can drive cars and planes, tell us the news, play chess and football, or compose music. Factory work is currently being done by industrial robots.

4. Internet of things-Although it was mentioned above as part of the challenges facing the telecommunications industry due to the huge amount of data that connected devices generate, but it is one of the major trends that will provide telecommunications companies with more opportunities in the coming years. By becoming an IoT communications service provider and offering Machine to Machine (M2M) devices, you can open up new revenue streams for Telecom companies. Gartner predicts that by 2020 , about 20 billion devices will be connected to the IoT, and revenue from IOT product and service providers will be $\$ 300$ billion. According to a study conducted by Tata Consultancy Services (TCS), the telecommunications sector ranks fourth in terms of spending on IoT technologies. Creating software updates for their products and services has been praised by telecommunications companies as the best business process improvement. Other business improvements include customized marketing campaigns, improved customer segmentation, and improved service quality.

5. Mergers and acquisitions-In the face of fierce competition, new technological innovations destroying the existing customer base, the year for the telecommunications sector does not seem so easy. That's why a number of companies are looking for partners for media and content companies, such as AT \& T's proposed merger with Time Time Warner Inc.

There are also leaders in the industry. They can change from year to year. Determining which ones are the biggest depends on whether they look in terms of total sales or in terms of market capitalization. As of 2018 the five largest telecommunications companies by market capitalization are as follows:

1. Verizon (VZ), which provides wireless and wired services in addition to broadband and information services, has a current market capitalization of about $\$ 200$ billion. It remains attractive as a dividend provider because of its financial condition: it is the largest telecommunications company in the US, operating in 150 countries. This company, instead of being one of many in the telecommunications industry, is rapidly entering new markets, they have in terms of new technologies, such as: connect to fiber optic lines all homes and offices, it will provide all communications, from traditional television to high-definition television [8].

2. China Mobile Ltd (CHL), which has been in business only since 1997, has a market capitalization of approximately $\$ 185$ billion due to the growth in the use of cell phones and Internet services in China over the past 15 years.

3. AT \& $\mathrm{T}(\mathrm{T})$, the oldest company in the telecommunications business, has a market value estimated at about $\$ 182$ billion. China Mobile has eclipsed AT \& T in just over a decade of its operations. Still, the former Ma Bell accounts for a third of the U.S. wireless market share and an impressive 30-year history of dividend increases.

4. Vodafone Group (VOD), the largest telecommunications company in the United Kingdom, provides services and equipment for voice, broadband and data, and its market capitalization is about 97 billion dollars [9].

5. Japan's SoftBank Corp, which provides it software as well as wireless and Internet services, has a current market capitalization of just over $\$ 90$ billion.

According to Kaufman, the change of the predominant source of growth in the economy leads to a new, next, way of life. The first and second modes were characterized by the dominance of raw materials, in the third mode, energy joined the raw materials, moving to the fourth mode. The fifth way is the development of information technologies. 


\section{Methodology}

To study the actual state, statistical data were considered, which can act as secondary data. The study also revealed the marketing environment of the telecommunications industry, where only the competitor is an important component.

Over the past decade, the telecommunications industry and related services have shown impressive results worldwide, becoming one of the key sectors of economic development, playing an increasingly important role in society. The telecommunications sector continues to grow. This can be seen in the table below.

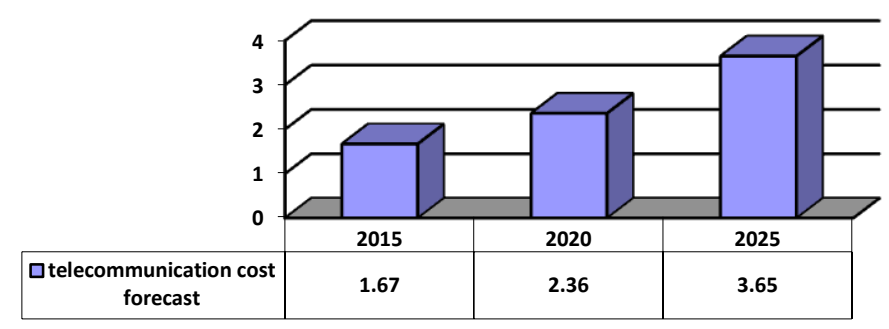

Fig. 1. Forecast of the cost of the telecommunication industry.

In 2018, compared to 2017, the volume of the global telecommunications market reached $\$ 1.62$ trillion, which actually shows an increase in this industry by $0.8 \%$. The data was released by IDC analysts in 2019 on may 10. At the same time, they previously estimated the market in 2015-2017 at \$1.67 trillion - with this in 2018, there was a decline.

In the market under consideration, most of the mobile communications covers, for reference in 2018 , their consumption was $53.1 \%$ of the global consumption, due to the high demand for smartphones. In addition, you can notice a decline in voice calls, which in turn give odds to other telecommunications services, such as WhatsApp, Skype. This may be due to the expensive rates for voice calls.

The following table shows the dynamics of the telecommunications market for geolocation.

Table 1. Telecommunications industry market dynamics by region, 2018.

\begin{tabular}{|c|c|c|}
\hline Global region. & Revenue for 2018 (\$t million). & Average for 2018-2023 (\%) \\
\hline America & 616 & 0 \\
\hline Asia & 512 & 0,8 \\
\hline $\begin{array}{c}\text { EMEA (Europe, Africa, } \\
\text { middle East) }\end{array}$ & 487 & 0,9 \\
\hline Subtotal & 1,615 & 0,5 \\
\hline
\end{tabular}

Telecom operators must be well prepared to take advantage of marketing and digitalization. The industry is facing a rapidly changing landscape driven by economic and technological shifts that could potentially transform the entire market. The share of operators in total industry profits fell from $58 \%$ in 2010 to $47 \%$ in 2015 , and is projected to decline further to $45 \%$ in 2019 . Consequently, it is increasingly important for operators to explore new digital business models, identify and implement new marketing tools to protect and expand their market share. 
Table 2. The market dynamics of the telecommunications industry by region, 2017.

\begin{tabular}{|c|c|c|}
\hline Global region. & Revenue for 2017 (\$t million). & Average for 2017-2018 (\%) \\
\hline America & 635 & 0,6 \\
\hline Asia & 545 & 3,5 \\
\hline $\begin{array}{c}\text { EMEA (Europe, Africa, } \\
\text { middle East) }\end{array}$ & 492 & 1,1 \\
\hline Subtotal & 1,672 & 1,7 \\
\hline
\end{tabular}

Table 3. Telecommunications industry market revenue by region, 2017-2018.

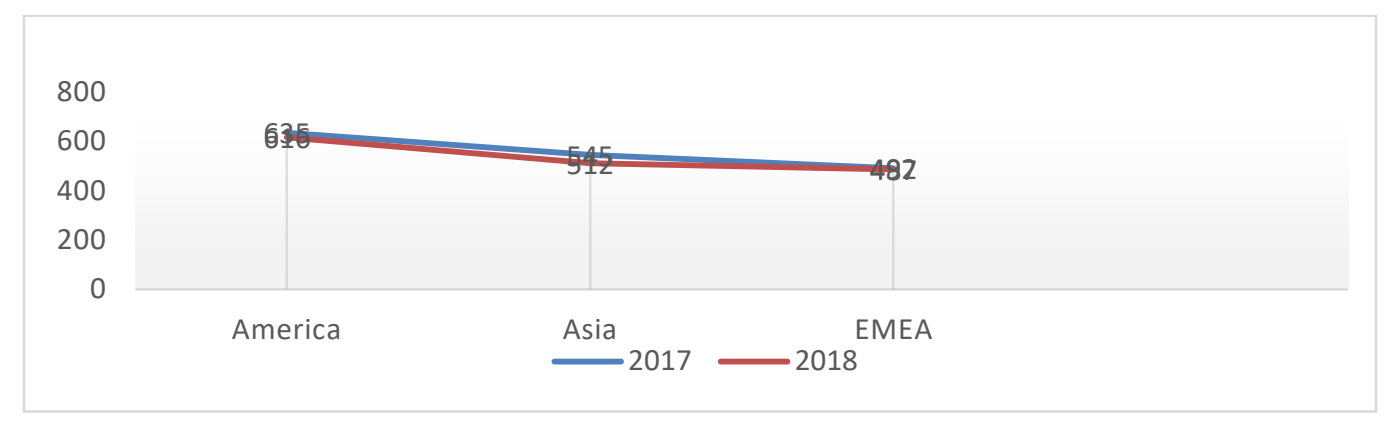

\section{Results and discussion}

On the above table you can see that the telecommunications industry market has shown good progress over the past two years. This in turn provides opportunities for further development of the industry by identifying new marketing moves, innovative technologies. According to the world economic forum, the Digital transformation of marketing in telecommunications represents a USD2tln opportunity for industry and society, ranging from 4 digital topics:

1. Networks networks of the future-virtualization and abstraction of the physical hardware layer promise to fundamentally change the basis of future technological differentiation through networking.

2. Beyond the tube-increasing digitization of consumers and businesses presents the telecommunications industry with not a few important opportunities to expand revenue streams.

3. Redefining customer engagement - to win the race for customer loyalty and thought-sharing, the telecommunications industry will need to increasingly deploy features and tools that provide digital marketing expertise.

4. Bridging the innovation gap-the need for rapid innovation, greater convergence and new services. This means that the telecommunications company needs to fill crucial gaps in the capabilities, using innovative new models and updated strategy for the digital workforce.

The marketing environment of a telecommunications operator consists of a macro-and micro-environment. The macroenvironment is represented by forces of a broader social plan that influence the microenvironment (factors of demographic, economic, natural, technical, political and cultural nature). The microenvironment is represented by forces that are directly related to the operator itself and its customer service capabilities, i.e. suppliers, marketing intermediaries, customers, competitors and contact audiences.

Thus, competitors are an important component of the marketing microenvironment of the telecommunications operator, without taking into account and studying which it is impossible to develop an acceptable strategy and tactics of functioning in the market. 
Due to the increasing demand for wireless and broadband Internet, the demand for equipment related to these methods of obtaining information has increased. According to the results of the survey, it was found that for the period 2013 - 2018, Infonetics Research predicts an increase in supplies by $57 \%$, while revenues during this time will increase by only $8 \%$.

\section{Conclusion}

Trends come and go every day. That is why telecommunications companies must use new technologies and always be ready for the next implementation. To do this, it is necessary to introduce and use PR services, sales promotion, etc.in the same way you can enter the leaders of the industry, despite the tough competitive environment. Although technology provides continuous improvement in the quality of telecommunications services, a key aspect of the interaction between customers and companies is currently the characteristics of the customer service process. In the conditions of saturation of the market of telecommunication services, individualization can be achieved through the formation and delivery of service products.

\section{References}

1. P. Kotler, K. Keller, Marketing management 14th edition. Prentice Hall (2011).

2. P. Doyle, P. Stern, Marketing management and strategy. Pearson Education (2006)

3. L. N. Nikolova, D. G. Rodionov, M. A. Bahauovna, Int. J. Econ. Fin. 6(2), 246252 (2016)

4. E. Ganebnykh, T. Burtseva, A. Petuhova, A.Mottaeva, , E3S Web of Conferences, 91,08035, (2019) doi.org/10.1051/e3sconf /20199108035TPACEE2018

5. A.V. Bataev, A. A. Gorovoy, A. B. Mottaeva, Proceedings of the 32nd International Business Information Management Association Conference, 88101,(2018)

6. J. Müller, E. Bohlin, J. Karpakka, C. Riis, K. E. Skouby, Telecom. Pol. 17(8), 623630 (1993).

7. Z. Li, Telecommunication 4.0. (2018).

8. A. Mottaeva, E3S Web of Conferences, 110, 02164, (2019) doi.org/10.1051/e3sconf /201911002164

9. W. R. Kerr, E. Moloney, Vodafone: Managing Advanced Technologies and Artificial Intelligence. (2018).

10. D. Shipley, D. Jobber, Mark. Manag. 30(3), 301-314 (2001) 